\title{
THE ROLE OF THE COURT IN PROVING CRIMINAL CASES: UNEXPECTED CROSS-INDUSTRY ANALOGIES
}

\author{
Aliya R. Sharipova \\ Bashkir State University, Ufa, Russian Federation
}

Introduction: consideration of the issue of truth in criminal proceedings is replaced by the issue of the active role of the court in collecting evidence. Avoiding rhetorical questions allows the discussion to be redirected from an ideological framework to a legal one. The purpose of the work is to identify the patterns of litigation of different branches of procedural law related to the participation of state bodies in the case in defense of a large public interest. It is assumed that the high interest of the authorized state bodies in making judgments in their favor in criminal cases and in arbitration tax cases leads to the same type of legal phenomena in these different proceedings. The determining method of the research was the method of comparative jurisprudence. Also, the study used the methods of historicism, system-structural analysis and synthesis. Results: on the example of criminal and arbitration tax cases, an adjustment of procedural law and its application to the needs of state bodies was found to facilitate their winning cases. This is manifested at the level of the introduction of "special" rules that facilitate proof for tax and law enforcement agencies. The period of work of the tax authorities without such adjustment was distinguished by an explosive growth in its quality. Conclusions: true adversarial nature allows government agencies to improve the level of their work in terms of proving the legally significant circumstances of court cases. The rejection of adversariality, replacing it with the active role of the court, entails the redistribution of part of the burden of proof to it, which has far-reaching negative consequences for the quality of justice in the categories of cases under consideration in general.

Key words: criminal process, arbitration process, adversarial nature, proof, truth, active role of the court, public interest.

Citation. Sharipova A.R. The Role of the Court in Proving Criminal Cases: Unexpected Cross-Industry Analogies. Legal Concept, 2020, vol. 19, no. 3, pp. 117-122. (in Russian). DOI: https://doi.org/10.15688/lc.jvolsu.2020.3.16

УДК 343.1

ББК 67.410 .2
Дата поступления статьи: 08.07.2020

Дата принятия статьи: 25.07.2020

\section{РОЛЬ СУДА В ДОКАЗЫВАНИИ ПО УГОЛОВНЫМ ДЕЛАМ: НЕОЖИДАННЫЕ МЕЖОТРАСЛЕВЫЕ АНАЛОГИИ}

\author{
Алия Рашитовна Шарипова \\ Башкирский государственный университет, г. Уфа, Российская Федерация
}

\begin{abstract}
Введение: рассмотрение вопроса об истине в уголовном процессе заменено вопросом об активной роли суда в собирании доказательств. Избегание постановки риторических вопросов позволяет перенаправить дискуссию из идеологических рамок в юридические. Цель работы состоит в выявлении закономерностей судебных процессов разных ветвей процессуального права, связанных с участием в деле государственных органов в защиту крупного публичного интереса. Предполагается, что высокая заинтересованность уполномоченных государственных органов в вынесении судебных решений в их пользу по уголовным делам и по арбитражным налоговым делам приводит к однотипным правовым явлениям в этих разных производствах. Определяющим методом исследования выступил метод сравнительного правоведения. Также в исследовании использованы методы историзма, системно-структурного анализа и синтеза. Результаты: на примере уголовных и арбитражных налоговых дел обнаружена подстройка процессуаль(9) ного права и его применения к нуждам государственных органов для облегчения выигрывания ими дел.
\end{abstract}


Проявляется это на уровне введения «особых» правил, облегчающих доказывание для налоговых и правоохранительных органов. Период работы налоговых органов без подобной подстройки отличался взрывным ростом ее качества. Выводы: истинная состязательность позволяет государственным органам повышать уровень своей работы в части доказывания юридически значимых обстоятельств судебных дел. Отказ от состязательности с заменой ее активной ролью суда влечет перераспределение на него части бремени доказывания, что имеет далеко идущие негативные последствия для качества правосудия по рассматриваемым категориям дел в целом.

Ключевые слова: уголовный процесс, арбитражный процесс, состязательность, доказывание, истина, активная роль суда, публичный интерес.

Цитирование. Шарипова А. Р. Роль суда в доказывании по уголовным делам: неожиданные межотраслевые аналогии // Legal Concept = Правовая парадигма. - 2020. - T. 19, № 3. - C. 117-122. - DOI: https://doi.org/ 10.15688/lc.jvolsu.2020.3.16

\section{Правильная постановка вопроса об истине}

Вопрос о необходимости установления истины в уголовном процессе, возможно, не только самый изученный, но и серьезно политизированный и тенденциозный [10]. Своей формулировкой он напоминает анекдот о распределении благ в колхозе: «Кто за то, чтобы отдать телевизор председателю? Кто - против Советской власти?» В самом деле, спорить «против истины» себе дороже, ведь она ощущается всеми нами как благо высшей ценности. Именно поэтому свои рассуждения мы будем связывать с решением вопроса об активной позиции суда по собиранию доказательств в уголовном процессе и всех иных процессуальных ухищрениях, оправдываемых той самой истиной, но не о ней самой.

\section{Общее и особенное в активной роли суда в разных судебных процессах}

Для начала обратим внимание на то, что регламентация полномочий суда, связанных с собиранием доказательств, принципиальных отличий не имеет ни между разными видами судопроизводств (уголовное, арбитражное, гражданское, административное), ни внутри уголовного процесса в зависимости от процедуры (общий порядок или с участием присяжных заседателей), но при этом фактически активность суда по разным судебным делам различается весьма значительно.

Один из факторов, предопределяющих такое различие, мы уже предполагали, - это средний уровень квалифицированности сторон, участвующих в деле: максимальный - в уго- ловном и арбитражном процессах, а минимальный - в административном и гражданском.

Другую, весьма значимую причину разного уровня активности разных судов по разным делам мы предполагаем в факте участия государства в лице его органов в качестве стороны по делу и, соответственно, наличия значимого государственного интереса в нем.

Видение судом своей роли в доказывании, по нашему мнению, точно не зависит от указания в законе на пресловутую «всесторонность», об утрате которой в УПК сожалеют многие процессуалисты. Ирония в том, что 3 из 4 процессуальных кодексов (все, кроме УПК) содержат прямую обязанность суда всесторонне исследовать дело, хотя арбитражному, гражданскому и административному процессу криминалисты легко прощают отсутствие стремления к истине любой ценой. Во всяком случае, никаких попыток рассмотреть этот вопрос в межотраслевом аспекте в уголовно-процессуальной науке не предпринималось. Интересно и то, что новейший процессуальный закон - Кодекс административного судопроизводства - впервые в качестве принципа закрепил состязательность «с оговоркой» - «при активной роли суда» (ст. 6, 14), однако процессуалистами эта активность трактуется исключительно как помощь слабой стороне, которая судится против государства [1], а не его нацеленность на выяснение истины.

Параллель между судебным производством по уголовным делам и арбитражным производством о признании незаконными (недействительными) ненормативных актов налоговых органов обусловлена наличием в этих делах мощнейшего публичного интереса, под которым, как правило, в литературе понима- 
ется интерес государственный, объективно совпадающий (также по мнению большинства исследователей) с интересами всего общества. Наличие публичного интереса практически не нужно обосновывать: в сфере уголовного процесса он презюмируется учеными до такой степени, что демонстрируется лишь на уровне риторики. Что касается важности налоговых дел для государства, ограничимся упоминанием того, что его бюджет (а значит, реальные силы и возможности во всех сферах функционирования) большей частью формируется именно из налогов.

Итак, полагаем, отобраны две важнейшие для государства группы судебных дел: уголовные и арбитражные налоговые ${ }^{1}$.

\section{Связь публичного интереса и особенностей судебного процесса с его участием}

На заре действия Налогового кодекса РФ и даже до его принятия (конец 1990-х начало 2000-х гг.) в арбитражных судах царила подлинная состязательность с теми интересными особенностями, которые закон и судебная практика сформировали в отношении проверяющих и привлекающих к ответственности государственных органов.

Основное отличие процесса обжалования решения налоговой инспекции о привлечении к ответственности (или об отказе в привлечении к ответственности) состояло в том, что она никак не могла пополнять свою доказательственную базу в суде в сравнении с той, какая была ею собрана к моменту вынесения оспариваемого акта. Достаточно характерный вывод суда в рамках этой тенденции звучал примерно так: «На момент вынесения решения инспекции спорные обстоятельства не подтверждались упомянутыми доказательствами в связи с их отсутствием у налогового органа, в этой связи эти доказательства не имеют правового значения для разрешения вопроса о законности решения налогового органа» [5].

Действовал и запрет суду собирать доказательства в целях устранения недостатков проведенной налоговой проверки [6]. Акцент в вопросе «истины» был серьезно смещен с «как было на самом деле» (сколько налогов объективно должен платить налогоплательщик) на «удалось ли налоговому органу в ходе проверки доказать этот размер налогов». Логика такого подхода была простой и понятной: устанавливается законность решения государственного органа на момент его принятия. Значит, независимо от того, как происходили события прошлого, предопределяющие размер налоговых обязательств плательщика, оценивает суд лишь правоту налогового органа, а не правоту его оппонента.

Последствия такого подхода представляются очень позитивными: это «обучение» работе налоговых органов, которые по итогу такой школы стали одними из самых эффективных среди российских государственных органов. Кроме того, это создание благоприятных инвестиционных условий, когда налогоплательщики уверены в том, что суд для них - место защиты их прав, а не придаток проверяющих. И, пожалуй, самый большой плюс предсказуемости судебной практики в этой сфере - это повышение собираемости налогов. Как бы парадоксально это ни звучало, но плательщики верят в суд, ведут бухгалтерию и позволяют себе, как максимум, лишь чрезмерную оптимизацию, тогда как те, кто суду и государству не доверяют, уходят «в тень» и становятся ближе к черте, разделяющей налоговые правонарушения и преступления.

К сожалению, государственная власть не захотела ограничиваться теми стратегическими преимуществами, которые сулит лояльный налогоплательщикам суд. Ради возможности «докручивать» в суде дела, по которым налоговые органы недоработали, в Налоговом кодексе РФ и в работе судов стали появляться тенденции, противоположные описанным выше. Нельзя, конечно, говорить о полном изменении вектора, однако формулировки судов стали более расплывчатыми: «При разрешении вопроса о назначении экспертизы по спорам, связанным с применением раздела V.1 Налогового кодекса РФ, следует принимать во внимание, направлено ли проведение экспертизы на устранение недостатков налоговой проверки, либо она необходима для устранения сомнений в достоверности и противоречий в представленных доказательствах» [2]. 


\section{ПРОЦЕССУАЛЬНОЕ ПРАВО: ВОПРОСЫ ТЕОРИИ И ПРАВОПРИМЕНЕНИЯ}

Отчасти подобные «уточнения» закона напоминают знаковое Постановление КС РФ от 8 декабря 2003 г. № 18-П, которым Конституционный Суд РФ «разрешил» проводить следственные и иные процессуальные действия по возвращенному судом прокурору уголовному делу, если это необходимо для восстановления нарушенных прав участников судопроизводства. Какой бы пробел в доказывании ни был допущен предварительным расследованием, это обязательно связано с чьими-то нарушенными правами, поскольку в уголовном процессе нет просто «отношений», есть только правоотношения. Наивно полагать, что идея Конституционного Суда РФ состояла в восстановлении прав обвиняемого: суд, рассматривающий дело, может восстановить их куда лучше органов уголовного преследования, просто оправдав подсудимого. Трудно представить себе ситуацию, когда обвиняемый заинтересован в возвращении дела прокурору, и странной кажется беспомощность суда с его универсальной юрисдикцией самому защитить всех остальных, кроме обвиняемого, участников процесса.

Несмотря на слова о восстановлении прав в этом примере и слова об устранении сомнений в предыдущем примере по налоговым делам, больше всего позиции двух высших судебных органов похожи на разрешение сделать «вторую попытку».

Думается, что случайными все эти изменения не назовешь. Очевидно, кому-то показалось, что налоговые органы слишком часто проигрывают дела в суде и нужно изменить «правила игры» таким образом, чтобы выигрывать им стало проще.

Аргумент о том, что это несправедливо и несостязательно, очевиден, мы не будем тратить время на его демонстрацию. В вопросах политики справедливость находится не на вершине приоритетов, чего никак нельзя сказать о правосудии.

Подстройка процессуального права и его применения под интересы какого-то участника еще и недальновидно с точки зрения интересов самого этого участника. В текущем моменте, конечно, налоговых дел выигрывать государственные органы стали больше, но как на них самих отразится стиль игры с запасным тузом в рукаве?

\section{Влияние состязательности на опыт доказывания}

Именно период истинной состязательности в арбитражном процессе научил налоговые органы доказыванию. Проследим на примере изменение подходов к нему. В 2000-х гг. арбитражные суды рассматривали огромное количество налоговых споров, что было связано, не в последнюю очередь, с низким качеством проверочных материалов налоговых органов. Высока была доля дел, по которым требования налогоплательщиков об отмене решений налоговых инспекций удовлетворялись. Так, в 2019 г. число соответствующих дел, рассмотренных в арбитражных судах, уменьшилось по сравнению с 2005 г. почти в 5 раз (с 48 до 10 тыс.), а доля удовлетворенных требований сократилась почти вдвое (с $73 \%$ до $39 \%$ ) [8; 9].

Существовала среди них определенная категория дел, в которых доначисление налогов и наложение штрафов были связаны с использованием бизнесом подставных юридических лиц. Основным аргументом такого использования было утверждение о том, что документы от имени этих организаций подписывались не их руководителями или иными уполномоченным лицами. Поначалу налоговые инспекции лишь констатировали визуальные различия в образцах подписей, обнаруженных ими непосредственно во время налоговой проверки, и проигрывали дела в суде, который указывал на то, что таким способом принадлежность подписи не устанавливается [7]. Ни о каком назначении экспертизы в суде речи даже не шло. Однако с течением времени налоговые органы научились доказывать свои выводы правильно и теперь, как правило, назначают в рамках мероприятий налогового контроля почерковедческие экспертизы [3].

Это всего один пример того, как трансформировалось представление налоговых органов о доказывании, в действительности их множество. Точно так же налоговые инспекции перестали проигрывать в суде свои дела из-за несоблюдения процедуры привлечения к налоговой ответственности и процедуры взыскания налогов, хотя еще 15 лет назад доля «формальных» причин отмены их решений была преобладающей. 
А.Р. Шарипова. Роль суда в доказывании по уголовным делам: неожиданные межотраслевые аналогии

Сказанное демонстрирует то, насколько в относительно короткий срок государственный орган без долгой истории и традиций смог усовершенствовать свою работу, научившись благодаря состязательному процессу доказыванию и соблюдению закона в своей работе.

Полагаем, что уголовный процесс не позволил органам уголовного преследования пройти даже непродолжительный период адаптации к нормальной состязательности в суде, не рискнув принять временно высокий уровень оправданий по причине низкого качества доказывания в досудебном производстве. Пробелы в доказательствах, допущенные стороной обвинения, суд по уголовным делам заполняет сам. Эта практика объясняется определенным набором аргументов: например, назначение экспертизы судом необходимо не для устранения недостатков расследования, а для решения противоречий между уже содержащимися в деле заключениями [4]. Но почему обвинение решается передавать в суд дело, в котором есть противоречия? И не его ли, обвинения, это, в конце концов, проблема?

В заключение отметим две тенденции судебных процессов с участием государственных органов. Первая заключается в том, что процессуальные особенности и исключения формируются по тем делам, где задействованы важнейшие государственные и общественные интересы (в нашем случае в уголовных и арбитражных налоговых делах). Вторая тенденция состоит в том, что по подобным делам суд принимает на себя часть бремени доказывания того самого государственного органа, предоставляя ему некие процессуальные «льготы».

\section{ПРИМЕЧАНИЕ}

1 Ради справедливости, налоговые дела рассматриваются и в судах общей юрисдикции, если налогоплательщиком выступает физическое лицо, не являющееся индивидуальным предпринимателем. Но размер налоговых обязательств (и соответственно степень заинтересованности государства) в них на порядок ниже по сравнению с налогами бизнеса, споры о которых рассматривают арбитражные суды.

\section{СПИСОК ЛИТЕРАТУРЫ}

1. Глодина, А. В. Сочетание принципа активной роли суда с отдельными принципами административного судопроизводства / А. В. Глодина // Административное право и процесс. 2018. - № 11. - С. 65-71.

2. Обзор практики рассмотрения судами дел, связанных с применением отдельных положений раздела V.1 и статьи 269 Налогового кодекса Российской Федерации, утвержденный Президиумом Верховного Суда РФ 16 февраля 2017 г. Доступ из справ.-правовой системы «КонсультантПлюс».

3. Постановление Арбитражного суда Уральского округа от 05.04.2019 № Ф09-1061/19. Доступ из справ.-правовой системы «КонсультантПлюс».

4. Постановление Президиума Воронежского областного суда от 04.10.2017. - Доступ из справ.правовой системы «КонсультантПлюс».

5. Постановление Федерального арбитражного суда Московского округа от 28.09.2009 № КА-А40/ 9743-09-п. - Доступ из справ.-правовой системы «КонсультантПлюс».

6. Постановление Федерального арбитражного суда Северо-Западного округа от 25.10.2011 по делу № А 56-6136/2011. - Доступ из справ.-правовой системы «КонсультантПлюс».

7. Постановление Федерального арбитражного суда Северо-Кавказского округа от 17.12.2007 № Ф08-7919/07-3075А. - Доступ из справ.-правовой системы «КонсультантПлюс».

8. Сводные статистические сведения о деятельности федеральных арбитражных судов за 2019 год // Официальный сайт Судебного департамента при Верховном Суде Российской Федерации. Электрон. текстовые дан. - Режим доступа: http:// www.cdep.ru/index.php?id=79\&item=5257 (дата обращения: 07.07.2020). - Загл. с экрана.

9. Справка о рассмотрении арбитражными судами Российской Федерации дел, возникающих из административных правоотношений в 2002-2005 // Официальный сайт Федеральных арбитражных судов. - Электрон. текстовые дан. - Режим доступа: http:/www.arbitr.ru/_upimg/ABB81B271F36 BCCF7626080C0119EE02_vas_05-4_adm.pdf(дата обращения: 07.07.2020). - Загл. с экрана.

10. Тарасов, А. А. Идеологическая составляющая учения об истине в уголовном процессе / А. А. Тарасов // Природа российского уголовного процесса и принцип состязательности: к 123-летию со дня рождения М.С. Строговича : материалы конф. (г. Москва, 24-25 окт. 2019 г.). Москва : МГУ, 2020. - С. 311-316. 


\section{REFERENCES}

1. Glodina A.V. Sochetanie printsipa aktivnoy roli suda s otdelnymi printsipami administrativnogo sudoproizvodstva [The Combination of the Principle of the Active Role of the Court with Certain Principles of Administrative Proceedings]. Administrativnoe pravo i protsess [Administrative Law and Process], 2018, no. 11, pp. 65-71.

2. Obzor praktiki rassmotreniya sudami del, svyazannykh s primeneniem otdelnykh polozheniy razdela V.1 i statyi 269 Nalogovogo kodeksa Rossiyskoy Federatsii, utverzhdennyy Prezidiumom Verhovnogo Suda RF 16 fevralya $2017 \mathrm{~g}$. [Review of the Practice of Courts Reviewing Cases Related to the Application of Certain Provisions of Section V.1 and Article 269 of the Tax Code of the Russian Federation", Approved by the Presidium of the Supreme Court of the Russian Federation on 16 February 2017]. Access from Reference Legal System 'KonsultantPlyus'.

3. Postanovlenie Arbitrazhnogo suda Uralskogo okruga ot 05.04.2019 № F09-1061/19 [Resolution of the Arbitration Court of the Ural District Dated 5 April 2019 no. F09-1061/19]. Access from Reference Legal System 'KonsultantPlyus'.

4. Postanovlenie Prezidiuma Voronezhskogo oblastnogo suda ot 04.10.2017[The Ruling of the Presidium of the Voronezh Regional Court of 4 October 2017]. Access from Reference Legal System 'KonsultantPlyus'.

5. Postanovlenie Federalnogo arbitrazhnogo suda Moskovskogo okruga ot 28.09.2009 № KA-A40/ 9743-09- $p$ [The Ruling of the Federal Arbitration Court of the Moscow District of 28 September 2009 no. KAA40/9743-09-p]. Access from Reference Legal System 'KonsultantPlyus'.

6. Postanovlenie Federalnogo arbitrazhnogo suda Severo-Zapadnogo okruga ot 25.10.2011 po delu № A56-6136/2011 [The Ruling of the Federal Arbitration Court of the North-Western District of
25 October 2011 no. A56-6136/2011]. Access from the Reference Legal System 'KonsultantPlyus'.

7. Postanovlenie Federalnogo arbitrazhnogo suda Severo-Kavkazskogo okruga ot 17.12.2007 № F08-7919/07-3075A [The Decision of the Federal Arbitration Court of the North Caucasus District of 17 December 2007 no. F08-7919/07-3075A]. Access from Reference Legal System 'KonsultantPlyus'.

8. Svodnye statisticheskie svedeniya o deyatelnosti federalnykh arbitrazhnykh sudov za 2019 god [Summary Statistics on the Activities of Federal Arbitration Courts for 2019]. Ofitsialnyy sayt Sudebnogo departamenta pri Verhovnom Sude Rossiyskoy Federatsii [Official Website of the Judicial Department at the Supreme Court of the Russian Federation]. URL: http://www.cdep.ru/ index.php?id=79\&item $=5257$.

9. Spravka o rassmotrenii arbitrazhnymi sudami Rossiyskoy Federatsii del, voznikayushchikh iz administrativnykh pravootnosheniy v 2002-2005 [Information on the Consideration by the Arbitration Courts of the Russian Federation of Cases Arising from Administrative Legal Relations in 2002-2005] Ofitsialnyy sayt Federalnykh arbitrazhnykh sudov [Official Website of the Federal Arbitration Courts]. URL: http://www.arbitr.ru/_upimg/ABB81B271 F36BCCF7626080C0119EE02_vas_05-4_adm.pdf.

10. Tarasov A.A. Ideologicheskaya sostavlyayushchaya ucheniya ob istine $\mathrm{v}$ ugolovnom protsesse [The Ideological Component of the Doctrine of Truth in Criminal Proceedings]. Priroda rossiyskogo ugolovnogo protsessa $i$ printsip sostyazatelnosti: $k$ 123-letiyu so dnya rozhdeniya M.S. Strogovicha: materialy konferentsii (g. Moskva, 24-25 oktyabrya 2019 g.) [The Nature of the Russian Criminal Process and the Principle of Adversariality: to the $123^{\text {rd }}$ Anniversary of the Birth of M.S. Strogovich: Conference Proceedings 24-25 October 2019]. Moscow, 2020, pp. 311-316.

\section{Information About the Author}

Aliya R. Sharipova, Candidate of Sciences (Jurisprudence), Associate Professor, Department of Criminal Law and Procedure, Bashkir State University, Zaki Validi St, 32, 450076 Ufa, Russian Federation, nord-wind23@mail.ru,rector@bsunet.ru,https://orcid.org/0000-0003-3254-5577

\section{Информация об авторе}

Алия Рашитовна Шарипова, кандидат юридических наук, доцент кафедры уголовного права и процесса, Башкирский государственный университет, ул. Заки Валиди, 32, 450076 г. Уфа, Российская Федерация, nord-wind23@mail.ru, rector@bsunet.ru, https://orcid.org/0000-0003-3254-5577 